\title{
Fracture Union in Closed Interlocking Nail in Femoral Fracture
}

\author{
Sahu RL,' Sikdar J' \\ 'M. M. medical college, Mullana, Ambala, Haryana, India.
}

\section{ABSTRACT}

Introduction: Fractures shaft femur is a major cause of morbidity and mortality in patients with lower extremity injuries. The objective of this study was to find out the outcome of Interlocking nail in fracture femur.

Methods: This study was conducted in the Department of Orthopaedic surgery in M. M. Medical College from July 2006 to November 2008. Seventy eight patients were recruited from Emergency and out patient department having closed fracture of femoral shaft. All patients were operated under general or spinal anesthesia. All patients were followed for nine months.

Results: Out of seventy eight patients, sixty nine patients underwent union in 90 to 150 days with a mean of 110.68 days. Touch down weight bearing was started on 2 nd post-operative day. Complications found in four patients who had non-union, and five patients had delayed union which was treated with dynamization and bone graft. The results were excellent in $88.46 \%$ and good in $6.41 \%$ patients.

Conclusions: We concluded that this technique is advantageous because of early mobilization (early weight bearing), less complication with good results and is economical.

Keywords: close reamed interlocking nail, dynamization, femoral shaft fractures, union

\section{INTRODUCTION}

Fractures shaft femur is a major cause of morbidity and mortality in patients with lower extremity injuries. ${ }^{1}$ Most fractures are sustained in young adults during high velocity injuries. It can be life threatening due to complications. ${ }^{2}$ There is considerable debate regarding the best method of treating femoral shaft fractures. ${ }^{3,4}$ A method closely approaching this perfection is intramedullary interlocking nails. It improves rotational stability, can be used for axially unstable diaphyseal fractures. ${ }^{5}$ This treatment modality has been the subject of controversy since its introduction because of concerns of damage to the medullary circulation, possibilities of fat embolism ${ }^{6,7}$ and complications of misapplication of the technique because of a lack of understanding of the biomechanical principles of intramedullary nail fixation, radiation exposure ${ }^{8}$ and the equipment required. The objective of this prospective study is to achieve the ultimate goal of fracture union and early rehabilitation, short hospitalization, and good fracture healing response.

Correspondence:

Dr. Ramii Lal Sahu

1151 B, Sector 32 B,

Chandigarh 260030, India.

Email: drrlsahu@gmail.com 


\section{METHODS}

This prospective study was carried out at Orthopaedics department of M. M. Medical College from July 2006 to November 2008. It was approved by institutional medical ethics committee. A total of 78 patients with fracture femur admitted to our institute were included in present study. A written informed consent was obtained from all the patients; they were explained about treatment plan, cost of operation, and hospital stay after surgery, and complications of anaesthesia. They were followed up after surgery, were clinically and radiologically assessed for fracture healing, joint movements and implant failure. According to the criteria the results are graded as excellent when the fractures unites within 16 weeks without any complication, good when union occur within 24 weeks with treatable complications like superficial infection and knee stiffness and poor when union occur before or after 24 weeks with one or more permanent complications like infection (osteomyelitis), implant failure, non-union, limb shortening and permanent knee stiffness. Delayed union was recorded when the fracture united between three to six months while nonunion was noted when union had not occurred after eight months of treatment Follow-up was done.

Patients with closed femoral fracture with age more than 16 years and presented within a week of the injury and did not have any previous surgical treatment for the fracture were included in the study.

Malnourished patients and those with open fractures, pathological fractures and fracture nonunion were excluded from the study.

Examination of patients was done thoroughly at the time of admission to exclude other injuries. In majority of the patients close reamed interlocking nailing of the femur was performed on seventh to fourteenth day after the injury. In patients who were not fit for surgery due to associated injuries to vital organs, were haemodynamically unstable or due to active infection at injury site, or were pyrexial delayed interlocking nailing was performed when their over-all condition improved. Patients were laid supine on the fracture table with traction pin in condyles of fractured femur. The fracture was reduced by traction and manipulation under image intensification. After preparing the femur in standard manner, an oblique skin incision was given on the proximal tip of greater trochanter upto $6-8 \mathrm{~cm}$ proximally and posteriorly. The fascia of gluteus maximus was incised in line with its fibers. Subfascial plane of the gluteus maximus identified and piriformis fossa palpated. Bone awl was used to locate exact entry point. Guide rod was introduced and advanced into the center of the distal fragment until the tip reached the epiphyseal scar. Reaming with power reamers was done, $2 \mathrm{~mm}$ over the selected diameter of interlocking nail. The type of nailing is ante grade interlocking nails.
Then this interlocking nail was introduced. There were 68 static nails used and 10 dynamic nails used (Table 4). Proximal locking was done with jig and distal locking with free hand technique. Wound was closed with suction drain in standard manner and antiseptic dressing was done. Drain was removed on $2^{\text {nd }}$ post-operative day. Rehabilitation such as touch down weight bearing was started on $2^{\text {nd }}$ post-operative day and sutures were removed on $14^{\text {th }}$ post-operative day. These patients were assessed clinically and radio logically for union timing at nine months following surgery. Patients were assessed for delayed union (more than 4-6 weeks postoperative) and non union (nine months following surgery). Stastical analysis was limited to calculation of percentage of patients who had unions, malunions, delayed unions, or non unions and Excellent, Good, and poor outcomes (Table 5).

Table 1. Age and sex variations in study group $(n=78)$

\begin{tabular}{lccc}
\hline \multicolumn{1}{c}{ Age } & Male & Female & Total \\
\hline Less than 40 & 45 & 7 & 52 \\
$40-60$ & 15 & 5 & 20 \\
More than 60 & 5 & 1 & 6 \\
Total & 65 & 13 & 78 \\
\hline
\end{tabular}

Table 2. Site of femoral fracture $(n=78)$

\begin{tabular}{lcc}
\hline Femoral site & No & Percentage \\
\hline Proximal $1 / 3^{\text {rd }}$ & 12 & 15.38 \\
Middle $1 / 3^{\text {rd }}$ & 52 & 66.66 \\
Distal $1 / 3^{\text {rd }}$ & 14 & 17.95 \\
\hline
\end{tabular}

Table 3. Percentage of cases who had unions, malunions, delayed unions, or non unions $(n=78)$

\begin{tabular}{lcc}
\hline & Total Cases & Percentage of cases \\
\hline Union & 69 & 88.46 \\
Non union & 4 & 5.12 \\
Delayed union & 5 & 6.41 \\
Malunion & 0 & 0 \\
\hline
\end{tabular}

Table 4. Types of nail $(\mathbf{n}=78)$

\begin{tabular}{ll}
\hline Static nails & 68 \\
Dynamic nails & 10 \\
\hline
\end{tabular}

Table 5. Out come of results of interlocking nails (n=78)

\begin{tabular}{lcc}
\hline Out comes & No & Percentage \\
\hline Excellent & 69 & 88.46 \\
Good & 5 & 6.41 \\
Poor & 4 & 5.12 \\
\hline
\end{tabular}

\section{RESULTS}

There were seventy eight patients in this study, sixty five patients were male and thirteen patients were females. Femoral fractures at middle one third were fifty two out of seventy eight, fractures in twelve cases were at proximal one third and fractures in fourteen 
cases were at distal one third (Table 1, 2). The patients were divided in three groups according to their age for simplicity. Young age group included those patients whose age was less than forty years. In this group there were seven females and forty five males. Middle age group included patients, who were between the ages of 40-60 years. This group included five females and fifteen males. Old age group included patients older than sixty years. This group consisted of one female and five males. Five patients were diabetics and four of them were taking insulin. One female patient was diabetic and was taking oral hypoglycemic. The clinical results of our study were rated on the basis of the criteria of union, nonunion ${ }^{9}$, delayed union or malunion. The patients were followed according to their clinical status. Sixty nine patients had union in 90 to 150 days with a mean of 110.68 . Ten of our patients had diabetes. Union was achieved in eight patients in 95-109 days with a mean of 103.38 (Table 3 ). Rehabilitation -We allowed our patients to start touch down walking with crutches on the 2nd day of operation as they feel comfortable. All patients, except two, started partial weight bearing on the 6 th week and full weight bearing on the $12^{\text {th }}$ week. These two patients had non weight bearing ambulation till the callus became visible on radiographs. They had comminution at fracture site (Winquest and Hensen type III). All of our patients had full range of motion of their knees and hips. Three patients out of Seventy eight complained post operative knee pain, which was spontaneously resolved in two weeks. Our ten patients needed dynamization within six weeks because of obvious gap at the fracture site in subsequent radiographs. This was due to over distraction of fracture during operation. They were dynamized before starting partial weight bearing. The screw of less critical stability was determined (the screw which was away from the fracture) and it was removed in local anaesthesia. There were five i.e. 6.41 $\%$ delayed unions which were treated by dynamization. In our study only four of our patients $(5.12 \%)$ was labeled as nonunion and was treated by bone graft and dynamization.

\section{DISCUSSION}

Interlocking intramedullary nailing has been advocated as the treatment of choice for femoral shaft fractures by many international centers. ${ }^{5,9}$ Complications after dynamic or simple nailing of an unstable fracture pattern include shortening (average of $2 \mathrm{~cm}$ ) and melioration that frequently requires reparation. To confirm the clinical observations that statically locked fractures heal and to prevent the complications from not locking unstable fractures, Brumback et al $^{9}$ prospectively treated one hundred femoral fractures with statically locked Russell-Taylor nails, regardless of comminution. All fractures united, and only two required dynamization for union. Lepore et al reported five out of 43 patients who underwent traditional nailing required dynamization to achieve union. In our center we routinely perform the locking in static mode. In this study all the fractures were treated with statically locked intramedullary nail. Sixty nine out of seventy eight patients were united with out any complication. Ten of our patients needed dynamization i.e. removal of proximal or distal screw before starting partial weight bearing. Five patients showed no radiological signs of union at 4th month. They were dynamized and were encouraged to walk with bearing full weight. Four of our patients had nonunion. One had comminution at fracture site i.e. Winquest and Hensen type-II. He was treated with bone graft. In our study union rate is $88.46 \%$ which is very close to the reported series. Numerous studies have documented $97-100 \%$ union rate after reamed locked nailing of femoral shaft fractures. Kropfl et al ${ }^{10}$ reported a union rate of $100 \%$ in a study of 81 femoral shaft fractures with locked intramedullary nailing. Imran et al $^{11}$ reported a study of 37 cases in which union rate was $100 \%$ without any complication. Javaid et al reported in their study that reamed interlocking nailing is the treatment of choice in femoral shaft fractures and they had $100 \%$ union rate without any complication. ${ }^{12}$ In our study union occurred in 90 to 150 days with a mean of 110.68 days which is very close to other studies. Brumback et $\mathrm{al}^{13}$ tested the safety and efficacy of immediate weight-bearing after locked intramedullary nailing of femoral fractures and found that this was safe if the construct had relatively high fatigue strength using two locking screws distally instead of one. In our study we did nailing after reaming the canal. This is a routine protocol in our center. There is reported literature which shows increased blood loss, increased operating time, increased risk of pulmonary embolism and adult respiratory distress syndrome after reamed interlocking nail. We have a reasonable policy to wait and stabilize the patient who has certain risk factors such as associated chest trauma and anemia etc. When the patient is stable and fit for surgery we perform close reamed statically locked intramedullary nail. The functional out come of patients with femoral shaft fracture is probably the most important consideration when deciding on the best mode of treatment for a particular fracture pattern (Table 4). Successful early fracture union in femoral shaft fracture is the most demanding outcome for good function in addition to other factors. A potential limitation of our study was the absence of a control group treated by a different modality. Thus we cannot actually determine if any other method of treatment would have led to different 
results. Nevertheless our results are better than those of the previous studies in which kuntcher nails or plates has been used.

\section{CONCLUSIONS}

Close reamed interlocking intramedullary nail in femoral shaft fractures is the treatment of choice, because patient rehabilitation is early, hospitalization is short, and fracture healing response is good. If proper equipments are available, and pre-operative assessment and post -operative care is adequately taken, it is a safe method for treating femoral shaft fractures.

\section{REFERENCES}

1. Salminen ST, Philajamaki HK, Avikainen VJ, Bostman OM. Population based epidemiologic and morphologic study of femoral shaft fractures. Clin Orthop. 2000; 372:241-9.

2. Catagni MA, Mendlick RM. Femoral fractures. Tech Orthop. 1996;11:160-73

3. Anderson RL. Conservative treatment of fractures of the femur. J Bone Joint Surg (Am). 1967;49-A: 1371-5.

4. Zickel RE. Fractures of the adult femur excluding the femoral head and neck: a review and evaluation of current therapy. Clin Orthop. 1980;147:93 -114.

5. Sultan S. Interlocked nailing of comminuted fractures shaft of femur. J Ayub Med Coll Abottabad. 2001;13(3):14-5.

6. Bone LB, Babikian G, Stegemann PM. Femoral canal reaming in the poly- trauma patient with chest injury: a clinical perspective. Clin Orthop. 1995;318:91- 4.

7. Norris BL. Pulmonary dysfunction in patients with femoral shaft fracture treated with intramedullary nailing. J Bone Joint Surg (Am). 2001;83-A:1162-8.

8. Kohlhass AR, Howard R. Radiation protection during interlocking Kuntscher nailing. Orthop Rev. 1982;11:83.
9. Brumback RJ, Toal TR Jr, Murphy-Zane MS. Immediate weight bearing after treatment of a comminuted fracture of femoral shaft with a statically locked intramedullary nail. J Bone Joint Surg (Am). 1999;81:1538-44.

10. Kropfl A, Naglik H, Primavesi C, Hertz H. Unreamed intramedullary nailing of femoral fractures. J Trauma. 1995;38:717-26.

11. Imran F, Tussadaq N, Ahmed Z, Khan AR, Malik G. Interlocking nail for long bone fractures. Fauji Found Health J. 2001;2(1):14

12. Zubair MJ, Mateen MA, Hussain A. Closed intramedullary nailing versus dynamic compression plating for femoral shaft fractures in adults. J Pakistan Inst Med Sci. 1997; 7(2)8(1, 2):499-504

13. Brumback RJ, Ellison TS, Poka A. Intramedullary nailing of femoral shaft fractures, long term effects of static interlocking fixation. J Bone Joint Surg (Am). 1990; 74-A:106 -112. 